PERINATAL HYPOXIA-ISCHEMIA CAUSES SEVERE BUT REVERSIBLE DEPRESSION OF BRAIN 3-ll-DOPAMTNE UPTAKE. F. Silverstef 01705 Silverstein, K. Buchanan, and M.V. Joh

Michigan, Sect. of Pediatric Neurology, Ann Arbor. Hycreasing neuronal activity and/or by disrupting presynaptic nerve terminals. Neurotransmitter (NT) uptake by synaptosomes is energy-dependent and requires intact membrane systems. To examine the relationship between NT release and neuronal damage, we compared changes in dopamine (D) turnover and synaptosomal 3II-D uptake in hypoxic-ischemic rat striatum. In 7 day ld rat pus, unilateral carotid artery ligation (UCL) \& exold rat pups, unilateral carotid to striatal D depletion and homovanillic acid (HVA) accumulation on the side of UCL: HVA/D= homovanillic acid (HVA) accumulation on the side of UCL: HVA $/ D=$
$2.27+.82$ vs. HVA $/ D=.13+.03$ on the opposite side $(n=20, p<.001$, t-test). In synaptosomes prepared from striatum of 22 pups treated in similar fashion, on the side of UCL there was a $76 \%$ reduction in $3 \mathrm{H}-\mathrm{D}$ uptake $(.12+.03 \mathrm{pmol} / \mathrm{mg}$ tissue vs. $.51+.04$ in 20 untreated controls, ( $p<.00 \overline{1}$, t-test). Uptake was reduced $47 \%$ on the opposite side $(.27+.05 \mathrm{pmol} / \mathrm{mg})$, similar to values found in pups subjected to hypoxia alone $(.31+.06)$. However, if pups in pups subjected to hypoxia alone were sacriffced 24 hours after UCL synaptosomes showed normal-
activity $(.53+.04$ pmol on side of UCL and $.55+.03$ on the oppoactivity $(.53+.04$ pmol on side of UCL and $.55+.03$ on the opposite side). The results suggest that immature $D$ nerve terminals exposed to hypoxia-ischemia are initially disrupted functionvolved in the initial depression and subsequent recovery is important for devising strategies to protect the brain from hypoxic-ischemic injury.

1706

MENINGITIS: A DEVASTATING COMPLICATION OF SERIAL LUMBAR PUNCTION (LP) THERAPY FOR POSTHEMORRHAGIC HYDROCEPHALUS (PHH). Kathleen M. Smith, Ruth B. Deddish, Edward s. Ogata, Northwestern University Medical Sch. Depts of Pediatrics, OB/Gyn, Chicago, IL.

Serial LP has been advocated as a safe therapy for relieving intracranial pressure in prematures with PHH. During two years, 26 of 122 premature infants with IVH developed PHH. One infant had grade II, 14 grade III $(54 \%)$, and 11 grade IV (45\%) IVH. Serial LP (daily or qod) was initiated for progressive ventriculomegaly. Twenty-two infants underwent 3-33 LP while 4 infants lomegaly. developed meningitis directly related to LP. This far exceeds the incidence of meningitis in our infants without PHH. Organthe incidence of meningitis in our infants without PHH. Organisms were Staphylococcus epidermitis (2), Enterobacter aerogenes, Klebsiella pneumoniae, and Candida albicans. We could not identify specific risk factors responsible for LP associated birthweight (1088 vs $1200 \mathrm{~g}), \mathrm{GA}$ ( $29 \mathrm{wks})$, and had similar clinical problems. The use of central venous catheters and the clinical proble concurrent administration of difficult (multiple attempts 12-15\%) and $12-15 \%)$ and traumatic (3-7\%) LP did not differ. infants with meningitis died while the other 4 required neuro-
surgery for progressing $\mathrm{PHH}_{\text {o }}$ of the 16 noninfected infants, 4 ultimately required neurosurgery and 1 died of complications of this procedure. LP meningitis greatly worsened PHH outcome. The risk of LP therapy must be carefully considered before treating PHH.

1707

PERIVENTRICULAR LEUKOMALACIA: INCIDENCE AND SIGNIFIby Philip L. Calcagno). Department of Pediatrics, Georgetown University Medical Center, Washington, D.C.

Portable cranial sonography was done on 389 infants with birth weights of $1750 \mathrm{~g}$ or less admitted to Georgetown University Hospital's Intensive Care Nursery during the 3-year period May 198 to April 1984. Periventricular leukomalacia(PVL) was diagnosed in 28 infants (7.2\%) with birthweights of $680-1730 \mathrm{~g}$ with appropriate gestational ages $26-33$ weeks. The lesions were bilateral in $89 \%$ and widespread along the ventricular borders in $86 \%$. Survival in the PVL group was $75 \%$, statistically not significant vival in the PVL group was $75 \%$,

Twenty of the 21 PVL survivors have been evaluated quarterly using the Bayley Scales of Motor (PDI) and Mental(MDI) Development and standard neurological criteria. All infants demonstrated generalized hypertonia/spasticity on follow-up to 6-35 months (mean 17.6 months). Ninety percent had severe motor deficits, and $75 \%$ had significant delay in mental scores (MDI). Cortical blindness was present in $25 \%$. The infants with significantly abnormal MDI and PDI (scores $<50)$ all had bilateral widespread PVL, in contrast to the infants within the normal range who demonstrated focal and/or unilateral lesions.

Conclusions: 1) PVL occurs in $7.2 \%$ of premature infants weighing $1750 \mathrm{~g}$ or less at birth; 2) significant neuro-developmental handicaps are present in infants with bilateral widespread PVL; and 3) infants with focal and/or unilateral lesions have a better chance for reasonable developmental outcome.

\section{$\dagger 1708$}

NEUROLOGICAL DISEASE IN INFANTS WITH AIDS. Madhav Suri, Shaleish Asaiker, Asha Gupta, Johanna Goldfarb, Aditya Kaul and Ram Kairam. New York Medical College, Westchester Count

of Pediatrics, Valhalla, NY 10595 gical examination of three We followed serially the neurological examination of three
. All three children, first seen $6-8$ months of infants with AIDS. All three children, first seen $6-8$ months
age came from families with high risk for AIDS: Haitian (1/3) and I.V. drug user $(2 / 3)$, all had failure to thrive, hepatosplenomegaly, lymphadenopathy and recurrent infections.

All exhibited a marked arrest of development, progressive corticospinal tract signs and impaired brain growth (microcephaly). Developmental delay was most skills while fine motor skills were relatively intact. The corticospinal tract signs skills were relatively intact. The corticospinal tract signs were progressive, presenting as ang to spastic rigidity. One child tendon reflexes and progrication on CT scan. One child died of had basal ganglion calcification on CT scan.

pneumococcal meningitis at 13 months of age.

Repeated cerebral spinal fluid culture

fungal and viral pathogens were negative. We postulate that the neurological dion with an agent that AIDS is caused by intrauterine infection the vulnerable period. interrupts neurological maturation during the vinal fluid may help Search for HTLV-III in
elucidate the etiology.

1709 COMPUTERIZED CRANIAL TOMOGRAPHY IN PATIENTS WITH 9 SOTOS' SYNDROME. Roberto Ta1amantes, Geraldine W. Greenberg. Baylor College of Medicine, Texas Children's Hospital, Department of Pediatrics, Houston.

Detailed assessment of patients with Sotos' Syndrome using current neuroradiographic procedures has not been widely reported. Twenty-one patients meeting the characteristics of this syndrome (Sotos, J. AJDC, Vo1. 131,1977) were studied. Seventeen had computerized cranial tomography, of which five were normal. of the remaining twelve, nine had ventricular dilatation, two had cerebral atrophy, and two had agenesis of the corpus callosum. In eight of the patients the dilatation was mild

nificant dilatation requiring a V.P. shunt.

Several clinical findings not described previously were noted: two patients had atrial septal defects, three had tracheomalacia, and two had strabismus. In addition one had hypothyroidism, a finding previously described.

This is the first study to present the findings of computerized cranial tomography from a large number of patients with Sotos' Syndrome. The role of these findings in the pathogenesis is unclear, but the significant incidence of ventricular dilatation, cerebral atrophy, and agenesis of the corpus callosum makes it evident that C.T. scan of the head is an important part of the initial evaluation of patients with Sotos' syndrome. Consideration must also be given to concurrent or associated disorders, such as cardiac anomalies, tracheomalacia, strabismus and hypothyroidism. $1710 \mathrm{Na}^{+}$) ELEVATES DEPRESSED BRAIN (Br) AMINO ACID LEVELS MYELINOLYSIS (CPM) Jean Holowach Thurston, Richard E. Hauhart. Washington U., Dept. of Ped.; Children's Hospital, St. Louis. Effects of Chr Hypo- $\mathrm{Na}^{+}$or rapid correction of Chr Hypo-Na on $\mathrm{Br}$ metabolism are unknown. Acute Hypo-Na $(4 \mathrm{~h})$ reduced $\mathrm{Br}$ [AA] in mice ( $\mathrm{J}$ Neurochem $24: 953$ (1975)). If similar findings occur in $\mathrm{Chr}$ Hypo-Na ${ }^{+}$, elevation of plasma (P1) $\left[\mathrm{Na}^{+}\right]$might el vate $\mathrm{Br}$ [AA] (J Neurochen $40: 240(1983))$. To test the hypo-
thesis 20-d-old mice were made Hypo- $\mathrm{Na}^{2}$ (4-d Pitressin $+2.5 \%$ dextrose); then treated $w 1$ th $1 \mathrm{M}$ and $0.9 \% \mathrm{NaCl}$ for $9 \mathrm{~h} . \mathrm{PI}\left[\mathrm{Na}^{+}\right]$ (neq/1) and $\mathrm{Br}[\mathrm{AA}]$ (mmol/kg) (mean $\pm \mathrm{SE}$ ) are given below. Measurement Control( $\mathrm{N}=3)$ Chr Hypo- $\mathrm{Na}^{+}(\mathrm{N}=5)$ Rapid $\mathrm{Na}^{+} \mathrm{Rx}$ \begin{tabular}{llll}
\hline P1 Na & $145 \pm 1$ & $104 \pm 4$ & $139 \pm 3$ \\
Br glutamate & $8.19 \pm 0.11$ & $5.22 \pm 0.47$ & $9.38 \pm 0.17$
\end{tabular} $B r$ aspartate $2.56 \pm 0.17 \quad 1.31 \pm 0.02 \quad 3.68 \pm 0.23$ Br aspartate $2.57 \pm 0.13 \quad 0.71+0.04 \quad 1.15 \pm 0.03$ Br GABA $\quad 2.03 \pm 0.06 \quad 1.56 \pm 0.07 \quad 1.87 \pm 0.08$ $\begin{array}{lrrr}\mathrm{Br} \text { taurine } & 2.03 \pm 0.78 \pm 0.66 & 3.48 \pm 0.87 & 5.20 \pm 0.49\end{array}$ Chr Hypo-Na ${ }^{+}$decreased $\mathrm{Br}[\mathrm{AA}] 23 \%$ to $74 \%(\mathrm{P}<0.005)$. Rapid elevation of $\mathrm{Pl}\left[\mathrm{Na}^{+}\right]$increased $\mathrm{Br}$ glutanate and aspartate levels above normal ( $14 \%$ and $44 \%$, respectively (resp.), $\mathrm{P}<0.014$ ); glycine and taurine levels were still reduced $(27 \%$ and $65 \%$, resp.,
$P<0.006)$. Osmotic disequilibrium or injury to endothelial celis could produce $\mathrm{Br}$ edema. Increased levels of glutamate and aspartate (neuroexcitatory) and decreased levels of taurine and glycine (neuroinhibitory) could relate to the hyperactivity and/or seizures and the neuropathology seen in experimental CPM. 